\title{
IMPACT OF UNCONTROLLED HbA1c ON THE OUTCOME OF TUBERCULOSIS TREATMENT IN TB PATIENTS WITH DIABETES
}

\author{
Oki Nugraha Putra ${ }^{1 *}$, Hardiyono ${ }^{1}$, Fitriyatul Rizkiyah ${ }^{1}$, Affan Yuniar N.H ${ }^{1}$ \\ ${ }^{1}$ Faculty of Pharmacy, Hang Tuah University, Surabaya, Indonesia \\ *Correspondence email: oki.nugraha@hangtuah.ac.id
}

\begin{abstract}
Pulmonary tuberculosis (TB) is an infection and communicable disease caused by Mycobacterium tuberculosis. One of the risks to develop active tuberculosis is diabetes mellitus (DM), with two or three times higher than TB patients without DM. Several studies have reported that DM was associated with poor clinical outcomes characterized by a delay of smear sputum conversion or culture conversion in TB patients with DM. However, very limited studies that analyze uncontrolled diabetes by HbA1c level with clinical outcome of TB treatment. This study aims to review the correlation between HbA1c levels and sputum or culture conversion in TB patients with DM. Pubmed, Web of Science, and Embase database were used to search and select the article. We included five studies that met the inclusion criteria. Smear conversion rate at two months was lower in TB patients with DM than those without DM. Uncontrolled HbA1c levels > 6.5\%-7.0\% were significantly associated with smear conversion of culture conversion for more than two months with a high risk of treatment failure. The positive level of smear sputum at 2-3 months or the end of the intensive phase becomes a strong predictor a failure treatment at the end of the advanced phase. It can be concluded that HbA1c levels delay the smear sputum or culture sputum for more than two months. This review highlights a need for more attention to control HbAlc levels in TB patients with DM to achieve a better outcome.
\end{abstract}

Keywords: Tuberculosis, Diabetes Mellitus, HbA1c, Smear Conversion, Culture Conversion

\section{INTRODUCTION}

Pulmonary tuberculosis (pulmonary TB) is an infectious disease caused by Mycobacterium tuberculosis and still an unresolved problem worldwide. About a third of the world's population is thought to have a latent infection of Mycobacterium tuberculosis, and $95 \%$ of them were found in developing countries. One of the risk factors for tuberculosis is diabetes mellitus (DM). ${ }^{1}$ It was supposed that diabetic patients have a dysregulation of the immune system that leads to tuberculosis development. Diabetic patients have several times fold risk of suffering from TB than those without DM. Based on the world health organization(WHO),
Indonesia is estimated as the fifth highest country with diabetes in $2025 .^{2}$

Several studies reported that diabetes mellitus has negative impacts on antituberculosis treatment. DM was significantly associated with culture sputum that was still positive after six months of treatment of antituberculosis. A meta-analysis study by Baker et al. showed different sputum culture conversion findings after 2-3 months of treatment with antituberculosis in TB patients with DM. The risk of treatment failure was 1.7 times higher than those without DM. ${ }^{3}$ A high risk of infection, especially tuberculosis among type 2 diabetes mellitus (T2DM) patients, may 
depend on HbA1c as a glycemic control parameter. Some studies including randomized trials and observational, have consistently shown that good glycemic control could reduce the risk of diabetic microvascular complications by $10 \%-25 \% .{ }^{4,5}$ However, the effect of HbAlc level on infections has not been examined in randomized trials. ${ }^{6,7}$ Because of the data from some observational studies, it was difficult to interpret the data from inconsistent results. Furthermore, the HbA1c level usually was measured at once in patients with prevalent diabetes, making it difficult to understand the importance of acute hyperglycemia or hyperglycemia for a long time. ${ }^{8}$

Hemoglobin A1c (HbA1c) is glycated hemoglobin and is considered as a mean glucose level over the past 90 days. $^{9}$ The measurement level of $\mathrm{HbA} 1 \mathrm{c}$ has a strong relationship with the prevalence of type 2 diabetes mellitus (T2DM) in numerous studies. In T2DM, patients with a high level of $\mathrm{HbA} 1 \mathrm{c}$ with more than $53 \mathrm{mmol} / \mathrm{ml}$ are associated with an increased risk of active pulmonary TB. ${ }^{10}$ An association between DM and time to sputum conversion in TB patients has been observed by Alisjahbana et al., who stated that the failure of sputum conversion at the end of the second month of treatment TB in TB patients with DM was higher than those without DM. Still, his study did not evaluate some factors that affect sputum conversion. ${ }^{11}$

Moreover, diabetes mellitus has been reported by several studies as the main factor that inhibits sputum conversion at the end of the second month of TB treatment. The proportion of sputum culture conversion at two months after the intensive phase of TB treatment in TB with T2DM was $17.1 \%$ and without DM was $18.3 \%$, and it seems to be similar. However, at the end of the advanced phase (four months), the positive culture was higher in T2DM patients (22.2\%) compared to patients without T2DM (9.6\%). ${ }^{11}$ A study by Wijayanto et al. stated that the level of $\mathrm{HbA} 1 \mathrm{c}$ more than $8 \%$ was associated with TB in T2DM patients. ${ }^{12}$
A high level of HbA1c would increase the risk failure of sputum smear conversion 2.3 more significant in TB patients with diabetes. Although many studies have reported that diabetes was one of the risk factors that impaired the outcome of antituberculosis drugs, few studies analyze the association between HbAlc and sputum smear or sputum culture conversion in TB patients with diabetes. However, most of the published studies were observational studies. These findings remain unclear because of the differences in sample type of TB patients, methods, time to diagnose DM during TB treatment, etc. In this review, we discussed whether a high level of HbA1c impaired the tuberculosis treatment of TB patients with DM in sputum smear or sputum culture conversion

\section{METHODS}

This review aims to determine whether uncontrolled HbA1c impaired the TB treatment in TB-DM patients compared to TB without DM in sputum smear or sputum culture conversion.

We collected the articles from Pubmed, Web of Science, and Embase database published in 2015-2020. We used published articles, both written in English and Indonesia. The keywords to search the articles were: tuberculosis AND "diabetes mellitus" AND (HbA1C or "glycemic control" AND "sputum smear conversion" or "sputum culture conversion" The selected articles, including titles and abstracts, will be read and screened that matches the purpose of this study.

We used the articles for both retrospective and prospective studies. The inclusion criteria in this review were: (1) studies both experimental design (randomized controlled trial) and observational (cohort, cross-sectional, and casecontrol) that analyze or discuss HbA1c, (2) patients were diagnosed pulmonary TB with diabetes as well as HbA1c data and sputum results were available, (3) all patients in both groups were measured sputum smear or sputum culture conversion at 2-3 months or sixth 
months. We excluded the articles if: (1)animal experiments study, (2) reviews, letters, brief communication and case report study, (3) pulmonary TB patients complicated with autoimmune or immunodeficiency diseases such as systemic lupus, rheumatoid arthritis which need long-term use of steroids, (4) multidrug-resistant (MDR-TB) and extrapulmonary TB.

\section{RESULTS}

Five studies met the inclusion criteria from several databases, as shown in table 1.

Table 1. Article Characteristics.

\begin{tabular}{|c|c|c|c|}
\hline Author and Year & Study Design & $\begin{array}{c}\text { Number of } \\
\text { Subjects }\end{array}$ & Findings \\
\hline $\begin{array}{l}\text { Ratnawatiet al., } 2018 \\
13\end{array}$ & $\begin{array}{l}\text { A prospective cohort study } \\
\text { of new cases of pulmonary } \\
\text { TB }\end{array}$ & 123 & $\begin{array}{l}\text { HbA1C level more than } 47.5 \mathrm{mmol} / \mathrm{ml} \text { was } \\
\text { a significant relationship with sputum } \\
\text { conversion for more than two months, RR } \\
6.3(1.9-39.6)(\mathrm{p}<0.05)\end{array}$ \\
\hline Kulsum et al., $2017^{14}$ & $\begin{array}{l}\text { A prospective cohort study } \\
\text { of new cases of TB }\end{array}$ & 84 & $\begin{array}{l}\text { After two months of intensive phase failures } \\
\text { in TB-DM patients, the proportion of } \\
\text { sputum conversion was } 43.04 \% \text { vs. } 22.75 \% \\
(p<0.05) \text {. HbA1C level is one of the risk } \\
\text { factors for conversion failure }(p=0.014)\end{array}$ \\
\hline $\begin{array}{l}\text { Oceguera et al., } 2015 \\
15\end{array}$ & $\begin{array}{l}\text { A retrospective study of TB } \\
\text { cases during five years }\end{array}$ & 88 & $\begin{array}{l}\text { Time to sputum conversion in patients } \\
\text { TB+DM with HbA1C more than and less } \\
\text { than } 6.5 \% \text { was } 68.9 \text { days vs. } 110.0 \text { days, } \\
\text { respectively }(\mathrm{p}>0.05) \text {. Time to culture } \\
\text { conversion in MDR-TB patients with DM } \\
\text { was } 93.5 \text { days vs. } 75.9 \text { days in MDR-TB } \\
\text { patients without DM }(\mathrm{p}>0.05)\end{array}$ \\
\hline Yoon et al., $2017^{16}$ & $\begin{array}{l}\text { A prospective cohort study } \\
\text { of pulmonary } \mathrm{TB}\end{array}$ & 661 & $\begin{array}{l}\text { TB patients with DM who had uncontrolled } \\
\text { diabetes }(\mathrm{HbA} 1 \mathrm{c}>7 \%) \text { were significantly } \\
\text { associated with the positive culture after two } \\
\text { months of treatment, treatment failure, and } \\
\text { death }(\mathrm{p}<0.05) \text {. Patients with controlled DM } \\
\text { has a favorable outcome treatment similar to } \\
\text { the non-DM group. }\end{array}$ \\
\hline Chiang et al., $2015^{17}$ & $\begin{array}{l}\text { A prospective cohort study } \\
\text { of pulmonary } \mathrm{TB}\end{array}$ & 1.473 & $\begin{array}{l}\text { Diabetic patients with HbAlc }>9 \% \text { were } \\
\text { significantly more likely to be smear- } \\
\text { positive than those without diabetes. }\end{array}$ \\
\hline
\end{tabular}

\section{DISCUSSION}

\section{The Correlation Between DM and Infection (TB)}

Pulmonary TB and DM are chronic and related diseases. Pulmonary TB will not recover sufficiently in uncontrolled diabetes. Pulmonary TB patients with DM have different characteristics, so they often undiagnosed, and therapy is challenging due to the interaction between TB drugs and oral antidiabetics. Factors associated with pulmonary $\mathrm{TB}$ in T2DM were close contact with other TB patients, the length of suffering from DM, and HbA1c levels. Wijayanto et al. reported that patients who have diabetes for a long time have a significant association with 
TB infection in DM patients (OR 23.13; CI 95\% 4.6-11), but it did not examine the relationships between the length of suffering from DM sputum conversion. ${ }^{12}$ Measurement of $\mathrm{HbA} 1 \mathrm{c}$ levels was more accurate to predict the prognosis of TB in TB-DM patients compared to blood glucose level. HbA1c level described blood glucose levels during the past 2-3 months and was not influenced by oral antidiabetic medication or food taken soon before the examination.

Several studies have reported that highlevel HbA1c was associated with increased TB infection risk, but many of them did not analyze the association with sputum conversion. A systematic review of the observational study by Jeon et al. reported that low blood sugar control or uncontrolled HbA1c significantly increases the risk of infection TB with a hazard ratio of 1.39 per unit of increase in HbAlc levels (CI 95\% 1.18-1.63). ${ }^{18}$ A study by Bartelink et al. stated that there was no significant difference in average levels of $\mathrm{HbA} 1 \mathrm{c}$ in T2DM patients with and without infection. In contrast, patients who had an infection during the follow-up period showed a higher level of HbA1c compared to patients without infection. Several studies have measured at once HbA1c levels on specifically selected infections. $^{19}$ A poor glycemic control characterized by a high level of HbA1c was associated with systemic infections, ${ }^{20,21}$ pneumonia requiring hospitalization, ${ }^{22}$ tuberculosis (TB), 23 urinary tract infections, ${ }^{24}$ and woman reproductive infection. ${ }^{25}$ A study by Critchley et al. stated that poor glycemic control in diabetic patients was significantly associated with severe infections such as bone and joint infection (46\%), tuberculosis (24\%), and sepsis $(21 \%){ }^{26}$

\section{Association Uncontrolled HbAlc With Therapeutic Outcome of Antituberculosis Treatment}

Several studies have reported uncontrolled diabetes, characterized by HbA1c level > 7\% among T2DM with TB. A study by Wahiduddin et al. stated that the HbA1c level in DM patients with pulmonary TB was higher (11.2\%) than those without pulmonary TB $(9.3 \%)$. This study was also reported that less than T2DM with TB achieving HbA1c level $<7 \% .^{27}$ Several studies reported a high proportion of uncontrolled diabetes with $\mathrm{HbA} 1 \mathrm{c}$ levels of more than $7 \%$ in T2DM with TB. Boyilla $\mathrm{N}$ et al. reported that in T2DM with pulmonary $\mathrm{TB}$, the proportion of $\mathrm{HbA} 1 \mathrm{c}>9 \%$ was $58.33 \%$, while $\mathrm{HbA} 1 \mathrm{c}<7 \%$ was $15.28 \%$. $^{28}$ Ahmed $\mathrm{M}$ et al. found most of the T2DM patients with pulmonary $\mathrm{TB}, 58.6 \%$ had uncontrolled HbA1c levels $(>6.5 \%) .{ }^{29}$ It indicated that the glycemic control in T2DM with TB was poor.

Based on table 1, all of the studies were observational with a cohort design. Studies reported that uncontrolled diabetes with HbA1c > 7\% was significantly associated with positive smear sputum or positive culture at a second month or the end of the intensive phase. One hypothesis showed that T2DM with TB impaired the antituberculosis treatment outcome. This condition is due to the immune dysregulation function. Several studies evaluating immune function in T2DM patients reported a dysregulation immunity, both innate and adaptive immunity. The dysregulation immunity was characterized by decreased interleukin 1 (IL-1) and IL-6 secretion by neutrophil cells and monocytes. It can decrease mobilization, chemotaxis, phagocytosis of phagocytic cells. It was also decreased $\mathrm{T}$ cell response and impaired humoral immunity. ${ }^{30,31}$ 
Natural killer (NK) cell functions and their relationship with glycemic control level have not been widely studied..$^{32} \mathrm{NK}$ cells are very important against viral and bacterial infections as well as control cancer growth. Meanwhile, T2DM patients with poor glycemic control have a higher risk of viral or bacterial infections and cancer. Previous studies reported a reduction activity of NK cells in $\mathrm{T} 2 \mathrm{DM},{ }^{33,34}$ but studies relating glycemic control and NK cells research activity were very rare. A study by Berrou et al. reported that a decreased NK cell activity in T2DM patients was negatively correlated with HbA1clevels. ${ }^{33}$ Several mechanisms are thought to explain these findings: hyperglycemia against the expression of glucose transporter (GLUT1, GLUT3, and GLUT4). ${ }^{35}$

Glucose is an important energy source for metabolism and cell activity, including immune cells such as leukocytes and NK cells. Impaired transporter expression of glucose will cause NK cells to lack energy and unable to activate their function. Besides, hyperglycemia in T2DM patients causes stress on the endoplasmic reticulum and leads to low expression of $\mathrm{NK}$ cell activation receptors such as NKG2D ${ }^{33}$. Furthermore, poor glycemic control in DM patients can disrupt NK cell activity, explaining DM patients' increased susceptibility against viral or bacterial infections and cancer. However, Ristanti et al. reported that the glycemic control did not significantly correlate with NK cell activity in T2DM. ${ }^{36}$

A study by Kulsum et al. reported that the median level of $\mathrm{HbA} 1 \mathrm{c}$ in the non-conversion group was significantly $10 \%$ higher than HbA1c levels in the conversion group (8.5\%). A high level of $\mathrm{HbA} 1 \mathrm{c}$ was also associated with increased failure of sputum conversion after correcting in albumin and acid-fast bacilli (AFB) positive level before antituberculosis treatment $(\mathrm{p}=0.018, \mathrm{aOR}$ 1.298 , CI $95 \%$ 1.047-1.610). ${ }^{14}$ The study by Jiyani et al. was also reported that $50 \%$ of patients who had sputum smear positivity before therapy $(3+)$ were TB-DM patients with HbA1c levels $>8 \%$. Still, this study did not analyze the relationship between $\mathrm{HbA} 1 \mathrm{c}$ levels and sputum conversion. ${ }^{37}$

In experimental animal models with chronic hyperglycemic, inflammatory cells and mediators are similar. It is even higher than that in euglycemic animals. However, there is a decrease in the cellular immune response. This was also characterized by inadequate binding and ingesting of the peripheral blood monocytes (PBM) with $M$. tuberculosis in T2DM patients. ${ }^{38}$ A proposed mechanism for the disability of macrophages to respond to $M$. tuberculosis in diabetic patients may be due to the reduction in nitric oxide production and $\mathrm{H}_{2} \mathrm{O}_{2}$ in the macrophages, ${ }^{39}$ processes in which PARP1 is actively involved..$^{40,41}$ Therefore, diabetic patients, especially with HbA1c levels above $8 \%$, were associated with a longer time to smear or culture conversion and a higher incidence of treatment failure

\section{Interaction of Diabetes With Antituberculosis Drugs}

It has been proposed that there were significant interactions between antituberculosis drugs and oral antidiabetic. And it was also worsening in the clinical outcome of TB patients with DM. Several studies have examined the effect of diabetes mellitus on the PK-PD of antituberculosis drugs. The results were contradictive or inconsistent. Several studies on TB patients with DM showed that the concentration of antituberculosis drugs was lower. ${ }^{42-44}$ While other studies reported no differences in antituberculosis concentration. ${ }^{45,46}$ 
Antituberculosis medications concentration on TB-DM patient's, especially rifampicin, was lower than in TB without DM. It was because of the alteration of drug absorption, distribution, and elimination (metabolism and excretion) in TB patients with DM. A study by Nijland et al. stated that the serum concentration of rifampicin in TB patients with DM was $53 \%$ lower than in TB patients without DM. A low concentration of antituberculosis drugs was predicted to cause poor clinical outcomes, and the risk of treatment failure was nine folds higher than that of high concentration. ${ }^{42}$

A study by Kusibawati et al. reported interaction between rifampicin and sulphonylurea, glipizid. It was found that rifampicin can stimulate the formation of cytochrome P-450 isoenzyme CYP2C9 to metabolize glizipid. Rifampicin accelerates the elimination of glipizid and lowers the glipizid concentration in blood circulation. Rifampicin is also proven to induce potent hepatic microsomal enzymes. Rifampicin also plays a role with another drug metabolism in the mixed-function oxidase (MFO) system. This system acts in a firstphase oxidase reaction in drug metabolism. ${ }^{47}$

An optimal therapy strategy for TB patients with DM has not been established. There is no best scientific evidence that supports the differences in regimen, especially antituberculosis drugs, between TB patients with and without DM. For TB patients with DM, the therapy and duration of antituberculosis medications are similar to TB patients without DM. In the intensive phase, four regimens of antituberculosis drugs (rifampicin, isoniazid, ethambutol, and pyrazinamide) are given daily for two months. In the advanced phase, rifampicin and isoniazid are administered daily or intermittently for four months, when blood sugar is well controlled. However, when blood sugar is poorly controlled, it will be extended to seven until nine months.

A systematic review reported that intermittent treatment in the advanced phase has a higher risk of treatment failure, relapse, and drug resistance than daily dose therapy. In 2017, WHO has no longer recommended intermittent treatment in the advanced phase. Interestingly, a study by Siane et al. stated that there were no differences between smear conversion and success rate in the advanced phase in TB patients with DM between daily and intermittent treatment. ${ }^{48}$ However, this study has some limitations. This study was a retrospective study from the medical record of TB-DM patients. The number of patients was relatively small, so it can't directly be applied to the general population.

A recent study by Alfarisi et al. reported that DM influenced pyrazinamide's pharmacokinetics. It also increases maximum concentration (Cmax) above the therapeutic concentration. A high level of Cmax of pyrazinamide was significantly associated with treatment failure, relapse, and death. The therapeutic concentration against Mycobacterium tuberculosis of rifampicin, isoniazid, and pyrazinamide is $8 \mathrm{mcg} / \mathrm{ml}, 3$ $\mathrm{mcg} / \mathrm{ml}$, and $35 \mathrm{mcg} / \mathrm{ml}$, respectively. Among the antituberculosis drugs, only pyrazinamide has a significantly lower TB concentration with DM than those without DM. In addition, an increase in HbA1c levels was followed by a decrease in pyrazinamide concentration. TB patients with DM, the concentration of rifampicin and isoniazid, were positively associated with time to culture conversion, but not with pyrazinamide concentration. ${ }^{49}$ In TB patients with DM, the rifampicin concentration was significantly reduced compared to TB patients without DM.

Interestingly, data from several studies were contradictory. Some studies reported a slower absorption and reduced rifampicin 
concentration. ${ }^{43}$ While others showed no significant effect of DM on the pharmacokinetics profile of rifampicin. ${ }^{50} \mathrm{It}$ was because of the differences in demographic patients, the severity of DM, the dose of antituberculosis drugs, and study design. In the continuous phase, rifampicin with a dose of $450 \mathrm{mg}-600 \mathrm{mg}$ was administered to TB patients thrice weekly or well known as intermittent dose and has been associated with worsened clinical outcome. Thus, a higher and daily dose of rifampicin is need ed to achieve a targeted clinical outcome.

A low concentration of isoniazid in TB patients with DM may be related to DMinduced intestinal motility changes. Due to isoniazid metabolization through $\mathrm{N}$ acetyltransferase 2 (NAT2), the rapid acetylators population reduces the plasma level of isoniazid ${ }^{51}$. Whether patients with DM should be administered a higher dose of antituberculosis was not clearly stated. An adequate dose of isoniazid (which reduces tuberculosis bacterial quickly) and rifampicin (which is the key sterilizing drugs) as the main anti-TB drugs in six months of therapy, including intensive and continuous phase, was needed to achieve sputum or culture conversion.

Insulin, oral hypoglycemic agent, and the combination between insulin and hypoglycemic agent improved the HbA1c level in T2DM with TB was observed by Wahiduddin et al. In T2DM with TB patients who uses insulin, oral hypoglycemic agent, and combination, HbA1c level was $10.29 \%$, $12.23 \%$, and $11.12 \%$ respectively. It was much higher than those without $\mathrm{TB} .^{27}$ However, this study did not report the type and dose of insulin and oral hypoglycemic agent that alter the HbA1c level, so it must carefully interpret in clinical settings.

Conversely, a hypoglycemic event resulting from the interaction between isoniazid and glimepiride was reported by Boglou et al. Primarily, glimepiride is metabolized in the liver via the cytochrome P450 isoenzyme CYP2C9 to its active metabolite and then metabolized to its dehydrogenated inactive metabolite. The inhibition process of cytochrome leads to the accumulation of parent drug glimepiride, resulting in hypoglycemia. Isoniazid, one of the antituberculosis drugs, is a strong inhibitor of CYP2C9 and other cytochrome $\mathrm{P} 450$ isoenzymes such as CYP2C19 and CYP2E1. Therefore, co-administration with glimepiride could increase its concentration in blood circulation. ${ }^{52}$ Thus, administration of isoniazid in DM patients, especially with concurrent acute illness who receive glimepiride may increase the risk of hypoglycemic events

\section{CONCLUSION}

From this review, it can be concluded that uncontrolled diabetes, which is characterized by a high level of $\mathrm{HbA} 1 \mathrm{c}>6.5$ $7.0 \%$, was significantly associated with delay of sputum smear conversion or culture conversion more than two months in TB patients with DM. Clinicians and pharmacists should collaborate to increase attention to HbA1c level or glucose level in TB patients with DM to achieve a better clinical outcome and reduce severe prognosis.

\section{REFERENCES}

1. Baghei $\mathrm{P}$, Marjani $\mathrm{M}$, Jsvanmard $\mathrm{P}$. Diabetes Mellitus and Tuberculosis Facts and Controversies. J Diabetes Metab Disord. 2013; 20(12):58

2. World Health Organization: Global Tuberculosis Report. [Online]. 2013. Available from: http://www.who.int/tb/publications/ global_report/en/. 
3. Baker MA, Harries AD, Jeon CY. The Impact of Diabetes on Tuberculosis Treatment Outcomes: A Systematic Review. BMC Med. 2011; 9:81.

4. Hemmingsen B, Lund SS, Gluud C. Targeting Intensive Glycaemic Control Versus targeting Conventional Glycaemic Control for Type 2 Diabetes Mellitus. Cochrane Database Syst Rev. 2013;(11) doi: CD008143.

5. Holman RR, Paul SK, Bethel MA. 10Year Follow-Up of Intensive Glucose Control in Type 2 Diabetes. N Engl J Med. 2008;359(15):1577-1589

6. Benfield T, Jensen JS, Nordestgaard BG. Influence of Diabetes And Hyperglycaemia on Infectious Disease Hospitalisation And Outcome. Diabetologia. 2007;50(3):549-554

7. Davis TM, Weerarathne T, Foong Y. Community Acquired Infections in Type 2 Diabetic Patients and Their Nondiabetic Partners. The Fremantle Diabetes Study. J Diabetes Complications. 2005;19(5):259-263.

8. Lynge E, Sandegaard JL, ReboljM. The Danish National Patient Register. Scand J PublicHealth. 2011;39(7 suppl):30-33.

9. Miedema K. Standardization of HbA1c and Optimal Range of Monitoring. Scand J Clin Lab Invest Suppl 2005;240:61-72.

10. Leung CC, Lam TH, Chan WM. Diabetic Control And Risk of Tuberculosis: A Cohort Study. Am J Epidemiol 2008;167(12):1486-1494.

11. Alisjahbana B, Sahiratmadja E, Nelwan EJ. The effect of Type 2 Diabetes Mellitus on The Presentation and Treatment Response of Pulmonary Tuberculosis. Clin Infect Dis. 2007;45(4):428-435

12. Wijayanto A, Burhan E, Nawas A. Pulmonary Tuberculosis in Patients With
Diabetes Mellitus Type 2. J Respirol Indones. 2015;35:1-11.

13. Rahmawati, Wijaya D, Nazaruddin AM. The Relationship Between Hemoglobin A1c Levels and Sputum Conversion Time in Indonesian Patients with New Cases of Pulmonary Tuberculosis. J Nat Sc Biol Med. 2018:9;217-221

14. Kulsum ID, Burhan E, Rochismandoko. Faktor yang Mempengaruhi Konversi Sputum BTA Mikroskopik Pada Pasien Tuberkulosis Paru Kasus Baru dengan Diabetes Mellitus. J Resp Ind. 2017; 37(2):109-118

15. Oceguara-Martinez D, LaborinLaniando R. Glycemic Control and Rate of Sputum Conversion in Diabetic Patients with Pulmonary Tuberculosis. Lung Dis Treat. 2016; 104. doi:10.4172/2472-1018.1000104

16. Yoon YS, Jung JW, Jeon EJ. The Effect of Diabetes Control Status on Treatment Response in Pulmonary Tuberculosis: A Prospective Study. Thorax 2017: 72 : 263-270

17. Chiang CY, Bai KJ, Lin HH. The Influence of Diabetes, Glycemic Control, and Diabetes-Related Comorbidities on Pulmonary Tuberculosis. 2015. Plos One. doi:10.1371/journal.pone.0121698

18. Jeon CY, Murray MB. Diabetes Mellitus Increases The Risk of Active Tuberculosis: A Systematic Review of 13 Observational Studies. PLoS Med. 2008;5:1091-101.

19. Bartelink ML, Hoek L, Freriks JP. Infections in Patients With Type 2 Diabetes in General Practice. Diabetes Res Clin Pract. 1998;40(1):15-19.

20. Thomsen RW, Riis AH, Kjeldsen .Impact of Diabetes and Poor Glycaemic Control on Risk of Bacteraemia With Haemolytic Streptococci Groups A, B, and G. J Infect. 2011; 63(1):8-16. 
ISSN 0216-3438 (Print). ISSN 2621-1122 (Online)

Kesehatan

21. McKane CK, Marmarelis M, Mendu ML. Diabetes Mellitus and CommunityAcquired Bloodstream Infections in The Critically Ill. J Crit Care. 2014;29(1):7076.

22. Kornum JB, Thomsen RW, Riis A. Diabetes, Glycemic Control, and Risk of Hospitalization With Pneumonia: A Population-Based Case-Control Study. Diabetes Care. 2008; 31(8):1541-1545.

23. Leegaard A, Riis A, Kornum JB, et al. Diabetes, Glycemic Control, and Risk of Tuberculosis: A Population-Based Case Control Study. Diabetes Care. 2011;34(12):2530-2535.

24. Hirji I, Guo Z, Andersson SW. Incidence of Urinary Tract Infection Among Patients With Type 2 Diabetes in The UK General Practice Research Database (GPRD). J Diabetes Complications. 2012;26(6):513-516

25. Hirji I, Andersson SW, Guo Z Incidence of Genital Infection Among Patients With Type 2 Diabetes in The UK General Practice Research Database. J Diabetes Complications. 2012;26(6):501-505.

26. Critichley JA, Carey IM, Harris T. Glycemic Control and Risk of Infections Among People With Type 1 or Type 2 Diabetes in Large Primary Care Cohort Study. Diabetes Care. 2018; 41(10):2127-2135

27. Wahiduddin, Pranoto A, Sudjarwo. Kendali glikemik pada pasien diabetes mellitus tipe 2 dengan dan tanpa tuberculosis paru. Jurnal MKMI. 2019;15(1): 99-109

28. Boyilla N, Madas S. Relationship between Diabetes Mellitus and Pulmonary Tuberculosis and Outcome of Treatment. International Journal of Advances in Medicine. 2016;(3):504-08.

29. Ahmed M, Omer I, Osman SM. Association Between Pulmonary
Jurnal Profesi Medika : Jurnal Kedokteran dan

Tuberculosis and Type 2 Diabetes in Sudanese Patients. The International Journal of Microbiology. 2017; (6): 97101

30. Flyvbjerg A. Diabetic Angiopathy, The Complement System and The Tumor Necrosis Factor Superfamily. Nat Rev Endocrinol. 2010;6(2):94-101.

31. Casqueiro J, Alves C. Infections in Patients With Diabetes Mellitus: A Review of Pathogenesis. Indian $\mathrm{J}$ Endocrinol Metab. 2012 ;16(Suppl1):2736.

32. Fidan I, Yüksel S, Kalkanci A. Evaluation of The Natural Killer Cytotoxicity and The Levels of Cytokines in Rats With Type I Diabetes Mellitus. Mem Inst Oswaldo Cruz. 2005;100(8):883- 887.

33. Berrou J, Fougeray S, Venot M. Natural Killer Cell Function, An Important Target for Infection and Tumor protection, Is Impaired in Type 2 Diabetes. PLoS ONE. 2013;8(4):e62418.

34. Menart-Houtermans B, Rütter R, Nowotny B. Leukocyte Profiles Differ Between Type 1 and Type 2 Diabetes and Are Associated With Metabolic Phenotypes: Results From the German Diabetes Study (GDS). Diabetes Care. 2014;37(8):2326-2333.

35. Piatkiewicz P, Czech A, Tatoń J. Glucose Transport in Human Peripheral Blood Lymphocytes Influenced by Type 2 Diabetes Mellitus. Arch Immunol Ther Exp (Warsz). 2007;55(2):119-126.

36. Ristanti Dian, Soegiarto G, Novida H. Hubungan Antara Kendali Glikemik Pada Pasien Diabetes Mellitus Tipe 2 Dengan Aktivasi Sel Natural Killer. Jurnal Penyakit Dalam Indonesia, 2019: 6(2): 58-63

37. Jiyani MR, Vadgama PK, Pandey AS. Clinical Profile and Outcome of 
Tuberculosis in Patients With Diabetes. Int J Res Med. 2015;4:36-40.

38. Gomez DI, Twahirwa M, Schlesinger LS. Reduced Mycobacterium Tuberculosis Association With Monocytes From Diabetes Patients That Have Poor Glucose Control. Tuberculosis (Edinb). 2013; 93(2): 192197.

39. Sugawara I, Mizuno S. Higher Susceptibility of Type 1 Diabetic Rats to Mycobacterium tuberculosis Infection. Tohoku J Exp Med .2008: 216: 363-370.

40. Buzzo CL, Medina T, Branco LM. Epigenetic Regulation of Nitric Oxide Synthase 2, Inducible (Nos2) by NLRC4 Inflammasomes Involves PARP1 Cleavage. Sci Rep.2017: 7:41686.

41. Mathews MT, Berk BC. PARP-1 Inhibition Prevents Oxidative and Nitrosative Stress-Induced Endothelial Cell Death Via Transactivation of The VEGF receptor 2. Arterioscler Thromb Vasc Biol.2008; 28:711-717.

42. Nijland HM, Ruslami R, Stalenhoef JE. Exposure To Rifampicin Is Strongly Reduced in Patients With Tuberculosis and Type 2 Diabetes. Clin Infect Dis. 2006: 43:848-854.

43. Medellin-Garibay SE, Cortez-Espinosa N, Milan-Segovia RC. Clinical Pharmacokinetics of Rifampin in Patients With Tuberculosis and Type 2 Diabetes Mellitus: Association With Biochemical and Immunological Parameters. Antimicrob Agents Chemother. 2015: 59:7707-7714.

44. Babalik A, Ulus IH, Bakirci N. Plasma Concentrations of Isoniazid and Rifampin Are Decreased in Adult Pulmonary Tuberculosis Patients With Diabetes Mellitus. Antimicrob Agents Chemother. 2013; 57:5740 -5742.
45. Ruslami R, Nijland HM, Adhiarta IG. Pharmacokinetics of Antituberculosis Drugs in Pulmonary Tuberculosis Patients With Type 2 Diabetes. Antimicrob Agents Chemother. 2010; 54:1068-1074.

46. Hemanth Kumar AK, Kannan T. Pharmacokinetics of Thrice-Weekly Rifampicin, Isoniazid and Pyrazinamide in Adult Tuberculosis Patients in India. Int J Tuberc Lung Dis. 2016: 20:1236 1241.

47. Kuswibawati, Pengaruh Pemberian Rifampisin Terhadap Efek Hipoglikemik Glizipid pada Relawan Sehat. Majalah Farmasi Ind onesia. 2003; 14(2):299-305.

48. Siane A, Ascobat P, Instiaty. Comparative Effectiveness of Tuberculosis Treatment Daily Versus Intermitten Regimen in Indonesian TBDM Patients: Real World Patient Database Study. Acta Med IndonesInd ones J Intern Med.2020, 52(1): 25-30

49. Alfarisi O, Mave V, Gaikwad S. Effect of Diabetes Mellitus on The Pharmacokinetics and Pharmacodynamics of Tuberculosis Treatment. Antimicrobial agents and chemotherapy. 2018; 62(1). doi: doi.org/10.1128/AAC.01383-18.

50. Requena-Mendez A, Davies G, Ardrey A. Pharmacokinetics of Rifampin in Peruvian Tuberculosis Patients With and Without Comorbid Diabetes or HIV. Antimicrob Agents Chemother. 2012; 56:2357-2363.

51. Wang $\mathrm{P}$, Pradhan K, Zhong XB. Isoniazid Metabolism and Hepatotoxicity. Acta Pharm Sin B. 2016;6(5):384 -392.

52. Boglou P, Steiropoulos P, Papanas N. Hypoglycaemia Due to Interaction of Glimepiride With Isoniazid in A Patients With Type 2 Diabetes Mellitus. BMJ 
ISSN 0216-3438 (Print). ISSN 2621-1122 (Online)

Kesehatan

Case Rep. 2013. doi:10.1136/bcr-2012008528 . 